\title{
BMJ Open A prospective study of adverse drug reactions to antiepileptic drugs in children
}

\author{
Mark Anderson, ${ }^{1}$ Oluwaseun Egunsola, ${ }^{1}$ Janine Cherrill, ${ }^{1}$ Claire Millward, ${ }^{1}$ \\ Apostolos Fakis, ${ }^{2}$ Imti Choonara ${ }^{1}$
}

To cite: Anderson M, Egunsola 0, Cherrill J, et al. A prospective study of adverse drug reactions to antiepileptic drugs in children. BMJ Open 2015;5:e008298. doi:10.1136/ bmjopen-2015-008298

- Prepublication history for this paper is available online. To view these files please visit the journal online (http://dx.doi.org/10.1136/ bmjopen-2015-008298).

Received 24 March 2015 Revised 1 May 2015 Accepted 7 May 2015

\section{CrossMark}

\footnotetext{
${ }^{1}$ Academic Division of Child Health, University of Nottingham, Derbyshire Children's Hospital, Derby, UK

${ }^{2}$ Department of Research and Development, Royal Derby Hospital, Derby, UK

Correspondence to Dr Oluwaseun Egunsola; mzxoe@nottingham.ac.uk
}

\section{ABSTRACT}

Objectives: To prospectively determine the nature and rate of adverse drug reactions (ADRs) in children on antiepileptic drugs (AEDs) and to prospectively evaluate the effect of AEDs on behaviour.

Setting: A single centre prospective observational study. Participants: Children ( $<18$ years old) receiving one or more AEDs for epilepsy, at each clinically determined follow-up visit.

Primary and secondary outcomes: Primary outcome was adverse reactions of AEDs. Behavioural and cognitive functions were secondary outcomes.

Results: 180 children were recruited. Sodium valproate and carbamazepine were the most frequently used AEDs. A total of 114 ADRs were recorded in 56 of these children (31\%). 135 children $(75 \%)$ were on monotherapy. 27 of the 45 children (60\%) on polytherapy had ADRs; while $29(21 \%)$ of those on monotherapy had ADRs. The risk of ADRs was significantly lower in patients receiving monotherapy than polytherapy (RR: $0.61,95 \% \mathrm{Cl} 0.47$ to $0.79, \mathrm{p}<0.0001$ ). Behavioural problems and somnolence were the most common ADRs. 23 children had to discontinue their AED due to an ADR.

Conclusions: Behavioural problems and somnolence were the most common ADRs. Polytherapy significantly increases the likelihood of ADRs in children.

Trail registration number: EudraCT (2007000565-37).

\section{INTRODUCTION}

Adverse drug reactions (ADRs) are a major clinical problem in both paediatric and adult medicine. Systematic reviews and metaanalyses of prospective studies of drug surveillance in children have showed that one in 10 children in hospital will experience an ADR. ${ }^{12}$ Studies in the community suggest that at least one in every 500 children will experience an ADR each year. ${ }^{3}$ The actual number is likely to be greater than this as the majority of ADRs are unrecognised and unreported.

In 1988, it was identified that the majority of children who receive an antiepileptic drug (AED) as an outpatient will experience an ADR. $^{4}$ Since then, however, a significant

\section{Strengths and limitations of this study}

A prospective study of adverse drug reactions to all antiepileptic drugs used in a single centre.

- Cognition and behaviour were assessed using standardised tools.

- The planned sample size was not reached.

- Both monotherapy and polytherapy were assessed for drug toxicity.

number of newer AEDs have been introduced, each with their own new ADR profile. In a large study of fatal suspected ADRs in the UK, AEDs were the group of medicines most likely to be associated with a fatality. ${ }^{5}$ Studies in the USA have also suggested that AEDs are associated with a significant number of ADRs. ${ }^{6}$ There are significant ADRs in association with the newer AEDs. ${ }^{7}$ Additionally, the reporting of drug toxicity in clinical trials of AEDs is poor. ${ }^{8}$

Children with epilepsy have a higher incidence of behavioural problems than other children. ${ }^{9}$ Moreover, both old and new generation AEDs have cognitive and behavioural effects, which can be positive or negative. The cognitive and behavioural effects of AEDs have been previously described. ${ }^{10-12}$ However, these psychotropic effects are difficult to ascertain because the presence of seizure itself could alter mood and behaviour. ${ }^{13}$

The aims of the study were to prospectively determine the nature and rate of ADRs in children on AEDs and to prospectively evaluate the effect of AEDs on behaviour and cognitive function in children with epilepsy prior to, during and after treatment with AEDs.

\section{METHODS}

\section{Study design and patient recruitment}

This was a prospective observational study conducted between 2008 and 2011 at Derbyshire Children's Hospital. Children aged $<18$ years, attending outpatient clinics, and who were receiving one or more AEDs for any type of 
epilepsy were considered suitable for the study. Parents of the children were approached for consent, either at an outpatient appointment or during an inpatient stay.

Patients eligible for the study were considered for three possible groups. Children who were already receiving AEDs were recruited to group A-prospective surveillance only. At each clinically determined follow-up appointment, parents and the child were asked about any possible side effects. Details of the AED treatment, doses, seizures, etc. were recorded at each visit. Patients starting AED therapy for the first time (group B) had measurements of behaviour and cognitive function performed prior to starting treatment and 12 months after starting treatment (table 1). Patients who had been seizure free for a period of 12 months (group C) had measurements of behaviour and cognitive function performed while receiving AED therapy. Those who remained seizure free for a further period of 12 months and for whom the clinician in charge of the patient had decided to wean off AED therapy had further assessments 3 months after treatment was stopped, that is, at 18 months.

\section{Behaviour and cognitive function monitoring}

Assessments of behaviour and cognitive function were performed by a clinical psychologist in subgroups B and C. Behavioural problems were quantified by using the Child Behaviour Checklist (CBCL); the Teacher Report Form (TRF), for children aged 5 years and over; and the Youth Self-Report Form (YSRF), for young people aged 11 years and older. Permission was obtained from the copyright holder to use the CBCL, TRF and YSRF for this study. Child Behaviour Checklists were available for the two age groups: $1.5-5$ years and $6-18$ years. If the child crossed between these age groups during the course of the study (ie, from 5 to 6 years), the same agespecific CBCL which was used during the first visit was then used for subsequent visits. The CBCL, TRF and YSRF have been used extensively in studies of behavioural problems in children. ${ }^{14-16}$ Concern, however, was raised that some of the items measured in the CBCL were ambiguous in relation to children treated with epilepsy. ${ }^{15}$ In view of this ambiguity, the CBCL was corrected for epilepsy-related item ambiguity as illustrated by workers in the Netherlands. ${ }^{16}$

\begin{tabular}{lll} 
Table 1 & Categories of patients recruited into the study \\
\hline Group & Patients & Intervention \\
\hline A & $\begin{array}{l}\text { All patients on } \\
\text { AEDs }\end{array}$ & Prospectively look for ADRs \\
B & $\begin{array}{l}\text { Newly diagnosed } \\
\text { (starting treatment) }\end{array}$ & $0,3^{*}$ and 12 months \\
C & $\begin{array}{l}\text { Seizure free for } \\
\text { 12 months }\end{array}$ & $\begin{array}{l}0 \text { and } 18 \text { months (assuming } \\
\text { no further seizures and }\end{array}$ \\
& 3 months weaning off AEDs)
\end{tabular}

${ }^{*}$ Behavioural tests only.

AEDs, antiepileptic drugs; ADRs, adverse drug reactions.
Children were asked to complete an assessment of cognitive functioning. The Wechsler Intelligence Scale for Children (WISC-IV) was used to assess children aged 6-16 years. Children of age 4-6 years were tested using the Wechsler Preschool and Primary Scale of Intelligence Third Edition (WPPSI-III). The tests were performed at study entry and at 12 months for group B, and at study entry and 18 months for group C (table 1).

\section{Definition of terms and causality assessment}

Causal relationship between ADR and treatment was assessed by a researcher, with the Naranjo Algorithm ${ }^{17}$ and by a paediatric clinical pharmacologist based on clinical judgement. This ensured standardised assessment of suspected ADRs in relation to severity and likelihood. On the Naranjo algorithm, a score of $>9$ suggests a definite attribution to the drug; 5 to 8 indicates a probable cause, 1 to 4 for possible relationship and doubtful association if the score is $<0$. Using clinical judgement, all suspected ADRs were also classified as: Definite-directly attributable to a drug by having a clear temporal relationship to drug administration and confirmed by laboratory investigation, for example, abnormal blood values; Probable-occurring with a clear temporal relationship to drug administration and improving on withdrawal of treatment; Possible-some temporal relationship to drug administration but the effects could have been due to the basic or intercurrent illness or doubtful, if there was no relationship with the drug. These methods have previously been used in paediatric ADR surveillance studies. ${ }^{3} 18-21$

The severity of ADRs was classified as: Severe-fatal or potentially life threatening; Moderate-requiring treatment or prolonging the length of stay in hospital; Mild -no treatment required and no effect on length of stay in hospital. ${ }^{3} 18$

\section{Sample size and statistical analysis}

The planned sample size was 300-400 children with epilepsy, with at least 50 children in groups $\mathrm{B}$ and $\mathrm{C}$ to observe $7 \mathrm{IQ}$ points difference from baseline (100 IQ Points) to follow-up, with statistical power $80 \%$ and significant level of 0.05 . Statistical analysis was mainly descriptive. Fisher's Exact Test was used to compare the relative risk of ADRs in patients on monotherapy or polytherapy. Cognitive and behavioural scores for children in groups $\mathrm{B}$ and $\mathrm{C}$ were compared during and after treatment using Wilcoxon Signed Rank Test. Statistical analysis was performed using SPSS v21 at significant level of 0.05.

\section{RESULTS}

\section{Study characteristics}

A total of 180 children were recruited into this study. A total of 141 children made up group A, 27 children were in group B and 12 children group C. The targeted sample size could not be reached over the course of the 
Table 2 Number (\%) of patients receiving different AED regimen

\begin{tabular}{llcc}
\hline Drug & Monotherapy (\%) & Polytherapy (\%) & Total (\%) \\
\hline Sodium valproate & $50(28)$ & $26(14)$ & $76(42)$ \\
Carbamazepine & $50(28)$ & $8(4)$ & $58(32)$ \\
Lamotrigine & $18(10)$ & $12(7)$ & $30(17)$ \\
Levetiracetam & $2(1)$ & $15(8)$ & $17(9)$ \\
Clobazam & 0 & $14(8)$ & $14(8)$ \\
Phenobarbitone & $6(3)$ & $6(3)$ & $12(7)$ \\
Topiramate & $3(2)$ & $9(5)$ & $12(7)$ \\
Ethosuximide & $6(3)$ & 0 & $6(3)$ \\
Phenytoin & 0 & $3(2)$ & $3(2)$ \\
Oxcarbazepine & 0 & $1(0.5)$ & $1(0.5)$ \\
Gabapentin & 0 & $1(0.5)$ & $1(0.5)$ \\
Clonazepam & 0 & $1(0.5)$ & $1(0.5)$ \\
Nitrazepam & 0 & $1(0.5)$ & $1(0.5)$ \\
\hline AED, antiepileptic drugs. & & &
\end{tabular}

study. The median age of the patients was 11.2 years (IQR: 6.9-14.0).

A total of 135 children were on monotherapy and 45 on polytherapy. Over half of the children received either valproic acid or carbamazepine as monotherapy. Seventy-four per cent of all AED prescriptions were old generation drugs. The most frequently prescribed drugs were sodium valproate $(33 \%)$, carbamazepine $(25 \%)$, lamotrigine (13\%) and levetiracetam (7\%; table 2).

\section{Adverse drug reactions}

A total of 114 ADRs were recorded in 56 of the 180 patients (31\%). Twenty-seven of the 45 patients (60\%) on polytherapy experienced ADRs. In contrast, 29 of the 135 children (21\%) on monotherapy experienced ADRs. The risk of ADRs was significantly lower in patients receiving monotherapy than those in polytherapy (RR: $0.61,95 \%$ CI 0.47 to $0.79, \mathrm{p}<0.0001$; figure 1 ). The majority of the ADRs occurred with the two most widely used AEDs-valproic acid and carbamazepine.

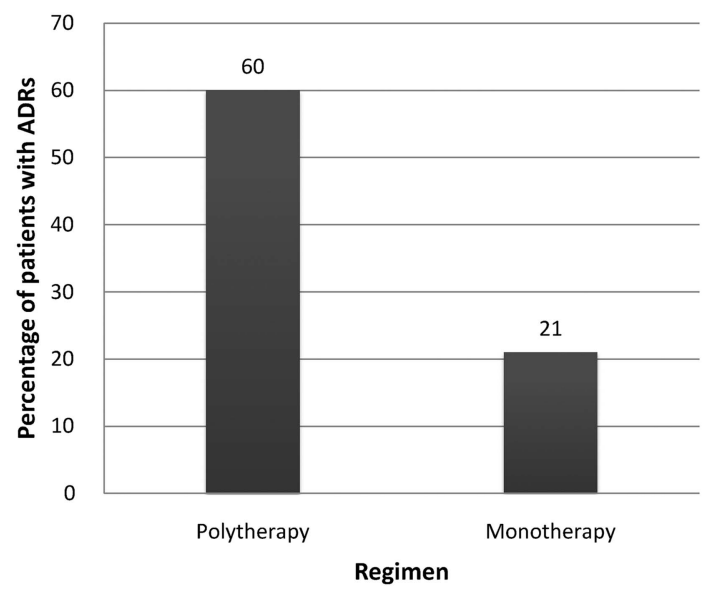

Figure 1 Percentage of patients on antiepileptic drugs monotherapy and polytherapy experiencing adverse drug reactions (ADRs).
The most common ADRs were behavioural problems and somnolence (table 3). These accounted for approximately one-third of all ADRs. Rash was the third most common ADR, and was most common with carbamazepine and lamotrigine.

AEDs were discontinued in 23 children (table 4). Dose was reduced in 20 patients. Approximately one in 10 children receiving valproic acid, carbamazepine and lamotrigine had to stop treatment due to toxicity. Behavioural problems were the most frequent reason cited for valproic acid, and rash for both carbamazepine and lamotrigine. All three children receiving phenytoin had to stop treatment for a variety of ADRs.

All but four ADRs were considered either probable or possible by both the Naranjo algorithm and the paediatric clinical pharmacologist. The majority were considered probable (57\% Naranjo and $79 \%$ by the paediatric clinical pharmacologist). Most ADRs were moderate $(61 \%)$ with three severe. The three severe ADRs were Steven Johnson syndrome (2) and respiratory arrest.

\section{Cognitive and behaviour functioning assessment}

On the Wechsler IQ scale, the median IQ score when on treatment was not significantly different from the score off treatment $(\mathrm{p}=0.411)$. Although there was a marginal increase in median score on the behaviour checklist and impact of epilepsy scale, these differences were not significant $(\mathrm{p}=0.354$ and 0.550 , respectively). Similarly, there was no significant difference in the score during treatment and post-treatment on the youth report form $(\mathrm{p}=0.838$; table 5$)$.

\section{DISCUSSION}

About one-third of patients receiving AEDs in this study developed at least one ADR during treatment. Carbamazepine, valproic acid and lamotrigine were the most frequently prescribed AEDs. A similar AED prevalence pattern has been reported in other studies. ${ }^{22-24}$ 
Table 3 Adverse reactions to antiepileptic drugs

\begin{tabular}{|c|c|c|c|c|c|}
\hline ADR & VPA & CBZ & LTG & Others & Total \\
\hline \multicolumn{6}{|l|}{ Psychiatry } \\
\hline Behavioural problems & 8 & 7 & 3 & TPM (1), PHT (1), LEV (2) & 22 \\
\hline Depression & 1 & 1 & - & - & 2 \\
\hline Anxiety & - & 1 & - & - & 1 \\
\hline \multicolumn{6}{|l|}{ Skin and appendage } \\
\hline Rash & - & 5 & 3 & PBT (1) & 9 \\
\hline Steven-Johnson syndrome & & & & PBT (1), PHT (1) & 2 \\
\hline Hair loss & 4 & - & - & - & 4 \\
\hline \multicolumn{6}{|l|}{ Metabolic } \\
\hline Increased appetite & 2 & 1 & - & - & 3 \\
\hline Reduced appetite & - & 1 & - & - & 1 \\
\hline Weight gain & 1 & 1 & - & - & 2 \\
\hline Polydipsia & 1 & - & - & - & 1 \\
\hline \multicolumn{6}{|l|}{ Nervous system } \\
\hline Somnolence/sleep disorders & 2 & 6 & 2 & CLB (4), ETX (1), PBT (1), PHT (1), LEV (1) & 18 \\
\hline Headache & 2 & - & 2 & - & 4 \\
\hline Fatigue & 2 & 2 & - & - & 4 \\
\hline Dizziness & - & 1 & 2 & - & 3 \\
\hline Blurred vision & - & 3 & - & - & 3 \\
\hline Poor concentration & - & - & - & TPM (1), LEV (1) & 2 \\
\hline Auditory hallucination & 1 & - & - & - & 1 \\
\hline Tremor & 1 & - & - & - & 1 \\
\hline Paraesthesia & - & - & - & TPM (1) & 1 \\
\hline Dystonia & - & - & - & PHT (2) & 2 \\
\hline Increased/new seizure & - & - & - & TPM (1), OXC (1) & 2 \\
\hline \multicolumn{6}{|l|}{ Gastrointestinal } \\
\hline Nausea & 2 & 2 & - & ETX (1) & 5 \\
\hline Vomiting & 1 & 2 & 1 & & 4 \\
\hline Abdominal pain & 1 & - & 1 & TPM (1) & 3 \\
\hline Diarrhoea & - & - & 1 & - & 1 \\
\hline \multicolumn{6}{|l|}{ Others } \\
\hline Fever & - & 1 & - & - & 1 \\
\hline Enuresis & 1 & - & - & TPM (1) & 2 \\
\hline Incontinence & - & 1 & - & - & 1 \\
\hline Renal stone & - & - & - & TPM (1) & 1 \\
\hline Respiratory arrest & - & - & - & Paraldehyde (1) & 1 \\
\hline Thrombocytopenia/bruising & 3 & - & - & LEV (1) & 4 \\
\hline Elevated ALT & 1 & - & - & - & 1 \\
\hline Gum hypertrophy & & 1 & & PHT (1) & 2 \\
\hline Total & 34 & 36 & 15 & 29 & 114 \\
\hline
\end{tabular}

ALT, alanine transaminase; ADRs, adverse drug reactions; CBZ, carbamazepine; CLB, clobazam; ETX, ethosuximide; LEV, levetiracetam; LTG, lamotrigine; OXC, oxcarbazepine; PBT, phenobarbital; PHT, phenytoin; TPM, topiramate; VPA, valproic acid.

These were also the most common causes of ADRs. The risk of treatment discontinuation was 1 in 10 patients for these three AEDs, with rash being the most common cause for carbamazepine and lamotrigine discontinuation. Others have shown similar discontinuation rates due to toxicity in children from carbamazepine and valproic acid; ${ }^{25}$ and carbamazepine and phenobarbital. ${ }^{26}$ Most AEDs are similar in efficacy but differ in safety. ${ }^{27} \mathrm{~A}$ large Chinese study had reported that similar proportions of children on carbamazepine, topiramate and valproic acid had adequate seizure control, while significantly more carbamazepine-treated children had treatment discontinuation due to ADRs, mainly rash. ${ }^{27}$ Han Chinese population, however, have a genetic predisposition to carbamazepine-induced rash. ${ }^{28}$ Carbamazepine is therefore not recommended as first-line treatment in Han Chinese without genotyping.

Most children in this study received monotherapy, with only $25 \%$ receiving polytherapy. Monotherapy for epilepsy became standard management in the 1970s as it was recognised that polytherapy was more likely to be associated with drug toxicity. ${ }^{29}$ AED used as monotherapy is effective in $60-70 \%$ of children. ${ }^{25} 2730$ Additional drugs in refractory patients have been shown to be only marginally beneficial. ${ }^{31}{ }^{32}$ Polytherapy is associated with a greater risk of drug toxicity in paediatric patients in general, ${ }^{18}{ }^{33}$ especially those receiving AEDs. ${ }^{34}$ More children receiving polytherapy in this study developed ADRs, with up to a threefold higher incidence of ADRs compared to monotherapy. Unfortunately, most new 
Table 4 Treatment discontinuation due to adverse reactions

\begin{tabular}{|c|c|c|}
\hline Drug & Adverse reaction & Patients (N) \\
\hline \multirow[t]{7}{*}{ Valproic acid } & Behavioural problems & 2 \\
\hline & Tiredness & 1 \\
\hline & Nausea, vomiting, abdominal pain & 1 \\
\hline & Hyperactivity, behavioural problems, tremor & 1 \\
\hline & Mood swing & 1 \\
\hline & Auditory hallucination & 1 \\
\hline & Total & 7 \\
\hline \multirow[t]{4}{*}{ Carbamazepine } & Rash & 4 \\
\hline & $\begin{array}{l}\text { Nausea ,vomiting, reduced appetite, incontinence, } \\
\text { behavioural problems }\end{array}$ & 1 \\
\hline & Gum hypertrophy & 1 \\
\hline & Total & 6 \\
\hline \multirow[t]{3}{*}{ Lamotrigine } & Rash & 2 \\
\hline & Dizziness, sleep disturbance, abdominal pain & 1 \\
\hline & Total & 3 \\
\hline \multirow[t]{4}{*}{ Phenytoin } & Steven-Johnson syndrome* & 1 \\
\hline & Dystonia, aggression, increased seizure & 1 \\
\hline & Gum hypertrophy, drowsiness & 1 \\
\hline & Total & 3 \\
\hline Phenobarbital & Steven-Johnson syndrome* & 1 \\
\hline Levetiracetam & Nose bleed & 1 \\
\hline Oxcarbazepine & Aggravated seizure & 1 \\
\hline Paraldehyde & Respiratory arrest* & 1 \\
\hline Total & & 23 \\
\hline
\end{tabular}

AEDs are tested by the pharmaceutical companies as add-on therapy and drug toxicity is poorly described in these studies. 8 This encourages clinicians to use polytherapy in epilepsy.

Since several of the AEDs share similar pharmacokinetic pathways, enzyme induction or inhibition may be a major problem with some drug combinations. ${ }^{35}$ One such combination is valproic acid and lamotrigine. Valproic acid inhibits lamotrigine glucuronidation, thereby increasing its plasma concentration and toxicity. ${ }^{36} 37$ AEDs also share similar pharmacodynamic mechanisms, which may have additive effects and increase the likelihood of ADRs. The use of AED combinations with different mechanisms of action has been advocated. ${ }^{35}$

There have been few pharmacovigilance studies of AEDs in children. ${ }^{48-40}$ The main ADRs identified in this study were behavioural problems (12\%) and somnolence/sleep problems $(10 \%)$. These were also the two most common ADRs in a previous study more than 20 years ago. ${ }^{4}$ Another study in India with a different
AED utilisation pattern reported a lower incidence of behavioural effects $(5.7 \%) .{ }^{38}$ While valproic acid and carbamazepine were the most commonly prescribed AEDs in this study, about two-third of the patients in the Indian study received phenytoin. We have reported no significant differences in cognitive and behavioural functions during and after AED treatment. A limitation of this study is the insufficient number of patients recruited. Much larger studies are required to adequately determine behavioural effects of AEDs. In addition, causality was assessed using the Naranjo algorithm, which is not paediatric specific. There is no paediatric specific tool to assess causality.

In conclusion, polytherapy increases the possibility of ADRs in children. Physicians should give AED polytherapy only when the maximum therapeutic doses of monotherapy are ineffective. Both clinicians and parents should monitor AED treated children for adverse reactions, especially behavioural problems and somnolence.

Table 5 Cognitive and behavioural scores for children in groups B and C during and after treatment

\begin{tabular}{llll}
\hline Method (no of children) & Median score on treatment (IQR) & Median score off treatment (IQR) & p Value \\
\hline Full scale IQ $(\mathrm{n}=26)$ & $90(86-103)$ & $91(83-105)$ & 0.411 \\
Child behaviour checklist $(n=26)$ & $23(13-41)$ & $25(13-52)$ & 0.354 \\
Impact of epilepsy scale $(n=27)$ & $20(16-27)$ & $23(14-28)$ & 0.550 \\
Youth report form $(n=10)$ & $41(13-65)$ & $32(13-62)$ & 0.838 \\
\hline
\end{tabular}


Contributors IC conceived the idea for the study. MA, JC and CM all contributed to the study design. MA, JC, IC and CM all collected data. OE, $\mathrm{MA}, \mathrm{JC}, \mathrm{AF}, \mathrm{CM}$ and IC analysed the data and contributed to the manuscript.

Competing interests None declared.

Ethics approval Trent Research Ethics Committee.

Provenance and peer review Not commissioned; externally peer reviewed.

Data sharing statement No additional data are available.

Open Access This is an Open Access article distributed in accordance with the Creative Commons Attribution Non Commercial (CC BY-NC 4.0) license which permits others to distribute, remix, adapt, build upon this work noncommercially, and license their derivative works on different terms, provided the original work is properly cited and the use is non-commercial. See: http:// creativecommons.org/licenses/by-nc/4.0/

\section{REFERENCES}

1. Impicciatore $P$, Choonara I, Clarkson A, et al. Incidence of adverse drug reactions in paediatric in/out-patients: a systematic review and meta-analysis of prospective studies. Br J Clin Pharmacol 2001;52:77-83.

2. Clavenna A, Bonati M. Adverse drug reactions in childhood: a review of prospective studies and safety alerts. Arch Dis Child 2009;94:724-8.

3. Bárzaga AZ, López LA, Mejías PY, et al. Pharmacovigilance in children in Camagüey Province, Cuba. Eur J Clin Pharmacol 2012;68:1079-84.

4. Choonara IA. Anticonvulsant toxicity in paediatric outpatients. Br J Clin Pract 1988;42:21-3.

5. Clarkson A, Choonara I. Surveillance for fatal suspected adverse drug reactions in the UK. Arch Dis Child 2002;87:462-7.

6. Le J, Nguyen T, Law AV, et al. Adverse drug reactions among children over a 10-year period. Pediatrics 2006;118:555-62.

7. Wong ICK, Lhatoo SD. Adverse reactions to new anticonvulsant drugs. Drug Saf 2000;23:35-56.

8. Anderson M, Choonara I. A systematic review of safety monitoring and drug toxicity in published randomised controlled trials of antiepileptic drugs in children over a 10-year period. Arch Dis Child 2010;95:731-8.

9. Bailet LL, Turk WR. The impact of childhood epilepsy on neurocognitive and behavioral performance: a prospective Iongitudinal study. Epilepsia 2000;41:426-31.

10. Aldenkamp AP. Effects of antiepileptic drugs on cognition. Epilepsia 2001;42(s1):46-9.

11. Brunbech L, Sabers A. Effect of antiepileptic drugs on cognitive function in individuals with epilepsy. Drugs 2002;62:593-604.

12. Weintraub D, Buchsbaum R, Resor S Jr, et al. Psychiatric and behavioural side effects of the newer antiepileptic drugs in adults with epilepsy. Epilepsy Behav 2007;10:105-10.

13. Drane DL, Meador KJ. Cognitive and behavioral effects of antiepileptic drugs. Epilepsy Behav 2002;3(5S):49-53.

14. Oostrom KJ, Schouten A, Kruitwagen CLJ, et al. Behavioral problems in children with newly diagnosed idiopathic or cryptogenic epilepsy attending normal schools are in majority not persistent. Epilepsia 2003;44:97-106.

15. Austin JJ, Dunn DW, Caffrey HM, et al. Recurrent seizures and behavior problems in children with first recognized seizures: a prospective study. Epilepsia 2002;43:1564-73.

16. Oostrom KJ, Schouten A, Kruitwagen CL, et al., Dutch Study Group of Epilepsy in Childhood (DuSECH). Epilepsy-related ambiguity in rating the child behaviour checklist and the teacher's report form. Epileptic Disord 2001;3:39-45.

17. Naranjo CA, Busto U, Sellers EM, et al. A method for estimating the probability of adverse drug reactions. Clin Pharmacol Ther 1981;30:239-45.
18. Turner S, Nunn AJ, Fielding $\mathrm{K}$, et al. Adverse drug reactions to unlicensed and off-label drugs on paediatric wards: a prospective study. Acta Paediatr 1999;88:965-8.

19. Dalvi PS, Singh A, Trivedi HR, et al. Adverse drug reaction profile of oseltamivir in children. $J$ Pharmacol Pharmacother 2011;2:100-3

20. Martinbiancho JK, Carvalho PRA, de Andrade Trotta E, et al Evidence of safety of chloral hydrate for prolonged sedation in PICU in a tertiary teaching hospital in southern Brazil. Eur J Clin Pharmacol 2009;65:1253-8.

21. Chalumeau M, Tonnelier $\mathrm{S}$, d'Athis $\mathrm{P}$, et al. Fluoroquinolone safety in pediatric patients: a prospective, multicenter, comparative cohort study in France. Pediatrics 2003;111:e714-e19.

22. Hamer HM, Dodel R, Strzelczyk A, et al. Prevalence, utilization, and costs of antiepileptic drugs for epilepsy in Germany-a nationwide population-based study in children and adults. J Neurol 2012;259:2376-84

23. Van de Vrie-Hoekstra N, De Vries T, Van den Berg P, et al. Antiepileptic drug utilization in children from 1997-2005-a study from the Netherlands. Eur J Clin Pharmacol 2008;64:1013-20.

24. Kwong KL, Tsui KW, Wu SP, et al. Utilization of antiepileptic drugs in Hong Kong children. Pediatr Neurol 2012;46:281-6.

25. Dudley RW, Penney SJ, Buckley DJ. First-drug treatment failures in children newly diagnosed with epilepsy. Pediatr Neurol 2009;40:71-7.

26. Banu SH, Jahan M, Koli UK, et al. Side effects of phenobarbital and carbamazepine in childhood epilepsy: randomised controlled trial. BMJ 2007;334:1207.

27. Ma MS, Ding YX, Ying W, et al. Effectiveness of the first antiepileptic drug in the treatment of pediatric epilepsy. Pediatr Neurol 2009;41:22-6.

28. Man CB, Kwan P, Baum L, et al. Association between HLA-B* 1502 allele and antiepileptic drug-induced cutaneous reactions in Han Chinese. Epilepsia 2007;48:1015-18.

29. Shorvon S, Chadwick D, Galbraith A, et al. One drug for epilepsy. Br Med J 1978;1:474-6.

30. Carpay HA, Arts WF, Geerts AT, et al. Epilepsy in childhood: an audit of clinical practice. Arch Neurol 1998;55:668-73.

31. Kanner AM, Balabanov AJ. The use of monotherapy in patients with epilepsy: an appraisal of the new antiepileptic drugs. Curr Neurol Neurosci Rep 2005;5:322-8.

32. Berg AT, Levy SR, Testa FM, et al. Remission of epilepsy after two drug failures in children: a prospective study. Ann Neurol 2009;65:510-19.

33. Thiesen S, Conroy EJ, Bellis JR, et al. Incidence, characteristics and risk factors of adverse drug reactions in hospitalized children-a prospective observational cohort study of 6,601 admissions. BMC Med 2013;11:237.

34. Pal A, Prusty SK, Sahu PK, et al. Drug utilization pattern of antiepileptic drugs: a pharmacoepidemiologic and pharmacovigilance study in a tertiary teaching hospital in India Asian J Pharm Clin Res 2011;4:96-9.

35. St. Louis EK. Truly "rational" polytherapy: maximizing efficacy and minimizing drug interactions, drug load, and adverse effects. Curr Neuropharmacol 2009;7:96-105.

36. Li L, Russo M, O'Donoghur M, et al. Allergic skin rash with lamotrigine and concomitant valproate therapy. Arq Neuropsiquiatr 1996;54:47-9.

37. Anderson GD, Yau MK, Gidal BE, et al. Bidirectional interaction of valproate and lamotrigine in healthy subjects. Clin Pharmacol Ther 1996;60:145-56.

38. Bansal D, Azad C, Kaur M, et al. Adverse effects of antiepileptic drugs in North Indian pediatric outpatients. Clin Neuropharmacol 2013;36:107-13.

39. Carpay JA, Vermeulen J, Stroink H, et al. Parent-reported subjective complaints in children using antiepileptic drugs: what do they mean? Epilepsy Behav 2002;3:322-9.

40. Lucas L, Telechea H, Speranza N, et al. Pharmacovigilance incorporation to clinical practice for hospitalized children ongoing antiepileptic treatment. Drug Saf 2008;31:885. 